\title{
Synthesis and physiological implications of melanic pigments (Review)
}

\author{
MINELA AIDA MARANDUCA ${ }^{1}$, DACIANA BRANISTEANU ${ }^{2}$, DRAGOMIR NICOLAE SERBAN ${ }^{1}$, \\ DANIEL CONSTANTIN BRANISTEANU ${ }^{3}$, GABRIELA STOLERIU ${ }^{4}$, \\ NICUTA MANOLACHE $^{4}$ and IONELA LACRAMIOARA SERBAN ${ }^{1}$
}

\begin{abstract}
Departments of ${ }^{1}$ Physiology, ${ }^{2}$ Dermatology, and ${ }^{3}$ Opthalmology, 'Grigore T. Popa' University of Medicine and Pharmacy, 700115 Iasi; ${ }^{4}$ Department of Dermatology, 'Dunarea de Jos' University, Faculty of Medicine, 800008 Galati, Romania
\end{abstract}

Received August 20, 2018; Accepted December 17, 2018

DOI: $10.3892 / 01.2019 .10071$

\begin{abstract}
The process of melanin synthesis and distribution is called melanogenesis, a process that is based on melanocytes present among the basal cells of the epidermis. Pigments formed in melanocyte melanosomes are then stored in the basal layer of epidermal cells, as well as in dermal macrophages, which become melanophores. From the embryological point of view, melanocytes derive from the melanoblasts of the neural crest, from where they migrate during the first months of life into the skin, eye, cochlea, bone, peripheral nervous system, heart and adipose tissue. The melanic pigments, eumelanin and pheomelanin, are the final product of complex biochemical reactions starting from the amino acid L-tyrosine. Melanin has a major role in skin homeostasis through the photoprotection it offers from the harmful effect of ultraviolet radiation. Melanin absorbs and/or reflects ultraviolet radiation but is also involved in the neutralizing process of free radicals and reactive oxygen species. Pigmentogenesis is a dependent oxygen process and is controlled by intrinsic factors (genetic and hormonal) as well as extrinsic factors (ultraviolet radiation). Melanogenesis is stimulated by stimulant melanocytic hormone, adrenocorticotropin hormone, estrogens and progesterone. The present review aimed to provide a summary of recent data about melanogenesis physiology.
\end{abstract}

\section{Contents}

1. Introduction

2. The melanocytes

3. The melanocortin 1 receptor

Correspondence to: Professor Daciana Branisteanu, Department of Dermatology, 'Grigore T. Popa' University of Medicine and Pharmacy, 16 University Street, 700115 Iasi, Romania

E-mail: debranisteanu@yahoo.com

Key words: melanin, skin, physiology, melanogenesis, ultraviolet radiation
4. Synthesis of the melanic pigments

5. Conclusion

\section{Introduction}

The synthesis and distribution of melanin (eumelanin, a yellowish-orange type of pigment and pheomelanin, a brownish-blackish pigment) bear the name of melanogenesis (1). Responsible for the synthesis of the melanic pigments are the melanocytes, neuroectodermic dendritic cells (2). Melanocytes represent $8 \%$ of the epidermis cells and have melanoblasts as precursors, cells which have their origin in the neural crest cells from the embryological point of view (3). At the same time with the closing of the neural tube (4), melanoblasts migrate in different regions of the organism such as the skin, peripheral nervous system, cartilage, bone, eye choroid, fatty tissue and cochlea (5). In the lower layer of the epidermis and at the level of the hair follicle, melanoblasts transform into melanocytes and become capable of fulfilling their basic function, that of secreting melanin (6). The process of migration, proliferation and differentiation of melanocytes are under the influence of the neural tube cells, ectoderm cells and keratinocytes, but also under the influence of the WNT glycoproteins family, endothelin 3 and of the stem cells factor (7).

Due to its specific chemical structure, the melanin molecule plays a role in the skin pigmentation and offers photoprotection to the organism by absorbing the sun ultraviolet radiation. The colour of the skin, hair and eyes is determined by the melanic pigments, and more precisely the ratio between the two types of melanic pigment. The quantity of melanic pigment offers the skin the colour from white (lack of melanic pigment) to black (increased melanin density), and the ratio eumelanin-pheomelanin determines the differences in pigmentation of the human skin (8). If the quantity of pheomelanin produced by the epidermal melanocytes is higher compared to the quantity of eumelanin, then the skin is of lighter color and has a higher susceptibility to the sun burns (9). In the skin containing a higher quantity of pheomelanin, following the exposure of the sun ultraviolet radiation, a higher quantity of reactive species of oxygen is produced, leading to a cellular lesion and initiating the carcinogen process (10-12). 
The quantity of synthesized melanin of melanocytes is genetically determined and depends on ethnicity but is also under the influence of intrinsic and extrinsic factors. The category of intrinsic factors includes molecules secreted by the melanocyte surrounding cells: keratinocytes, fibroblasts, inflammatory cells and endocrine cells (13). Ultraviolet radiation and various chemical products represent extrinsic factors which place their mark upon melanogenesis. The skin reaction to the various intrinsic and extrinsic factors is under the control of the cutaneous neuroendocrine system (14).

\section{The melanocytes}

From the level of the neural crest, melanocytes migrate towards various regions of the human body in the order to fulfil their primary function, that of synthesizing melanin. Melanoblasts, undifferentiated cells, reach not only the skin and hair follicle, but also the eyes, meninges, heart and cochlea, where they transform into melanocytes.

The synthesis and storing of melanin takes place in the cellular organelles specific to melanocytes, called melanosomes. Unique cellular organelles related to lysosomes, the melanosomes, derive from the young endosomes. Melanosomes have a different structure and function, according to the synthetized melanic pigment. While in the perinuclear region of melanocytes, melanosomes are immature and non-pigmented. As they migrate to dendrites, they undergo a series of conformational changes and become mature, pigmented and electron-opaque (15).

Melanosomes are present in black-skin people, melanocytes are larger, more elongated as well as numerous, and keratinocytes degrade more slowly.

In the epidermis, melanocytes are inserted into the keratinocytes due to their long and fine prolongations. A melanocyte is surrounded by 36 keratinocytes with which it forms the epidermal unit, whose activity is paracrine regulated. On the one hand, the synthesized quantity of melanic pigments at the melanocyte level is influenced (stimulated or inhibited) by a series of factors secreted by the keratinocytes, and on the other hand, melanocytes secrete a series of substances which act upon keratinocytes (16). Through extensions, the melanosomes of melanocytes are transferred to the surrounding keratinocytes (17), where they distribute uniformly in order to insure a homogeneous pigmentation and create a screen which covers the nucleus of keratinocytes (18). The transfer of the mature melanosomes to keratinocytes takes place when the $\mathrm{pH}$ of the extracellular environment increases from 5.0 to 6.8 (19). Keratinocytes take over melanosomes through a phagocytosis process (20), a process dependent on the ultraviolet radiation and regulated by the $\alpha$-melanocytic hormone ( $\alpha$-MSH) (21).

By way of $\alpha-\mathrm{MSH}$, following exposure to the sun ultraviolet radiation, the pigmentation of the skin is stimulated through the increase of the melanin synthesis, as well as proliferation and distribution of the epidemic melanocytes (16). Moreover, the number of dendrites of melanocytes, as well as the transfer rate of melanosomes at the level of epidermal unity is influenced by exposure to the sun ultraviolet radiation (16). Due to this placement, melanin protects the nuclear DNA from ultraviolet rays of solar light (22). The pigmentation process has the effect of increasing human skin resistance to sun burns (22).
An important role in the differentiation, proliferation and morphology of melanocytes has the glutamate pathway by activating the epidermal glutamate receptors (23). At the level of melanocytes and keratinocytes the glutamate receptors have been described (24).

The differences in the human skin pigmentation appear due to the various number of melanosomes in the keratinocytes (15). In order to fulfil the basic function, the life span and melanocyte resistance must be high. At the level of hair follicle, the melanic pigment synthesis takes place in the follicle unit made up of the follicle melanocytes, keratinocytes and the dermic papillary fibroblasts (22) which, compared to the epidermal unit, is larger. Synthesis of the melanic pigments in the skin is an ongoing process at the level of hair follicle. On the other hand, melanogenesis is active only during the hair anagenic (growth) phase (24) and is much more sensible to the aging process (25). The functioning of the epidermal unity is independent of the follicle unity. Melanocytes of the hair follicle have larger, more ramified melanosomes and the Golgi apparatus and rugged endoplasmic reticulum are better developed (26).

Melanocytes can migrate into the epidermis, dermis or dermo-epidermal junction and form cell nests. Under the influence of environmental factors, they turn into nevocites, giving birth to benign tumors, called nevi. Melanoma occurs as a result of nerve cell dysplasia (27).

Besides the epidermis and hair follicle, melanoblasts migrate to the level of the eye conjunctiva and in all the uveal areas (iris, ciliary body and choroid) and transform into melanocytes. It is not known precisely what the role of the conjunctive melanocytes is, but the melanocytes present in the uveal area provide protection against some eye diseases which can lead to blindness. As opposed to the skin, the colour of the iris remains stable following exposure to the sun.

Melanocytes are also present in the organs of the human body which are not exposed to the sun, where they fulfil other functions besides the photo-protection. Melanocytes at the level of the cochlea play a sgnificant role in hearing and balancing (28) by participating in endolymph synthesis. Melanocytes in the brain have a neuro-endocrine function and provide protection against oxidation processes (29), while their presence at the heart level is involved in the correct mechanic functioning of the valves (30) as well as atrial arrhythmia (31).

\section{The melanocortin 1 receptor}

The quantity of synthesized melanin is adjusted through the melanocortin 1 receptor (MC1R), which is located at the level of melanocyte membrane. MC1R belongs to the sub-group of the class A receptors coupled with $G$ protein. The linking of the extracellular ligands to this receptor leads to a series of cascading reactions, which begin with the activity of Gs protein. Gs protein presents seven trans-membrane domains and when it is activated it stimulates the enzymatic activity of the adenylate cyclase. The adenylate cyclase transforms the intracellular ATP into AMPc. The increase of intracytoplasmic AMPc affects the increase in the production of melanin as well as the increase of melanocyte resistance to the apoptosis and improvement of the genomic stability of melanocytes.

The eumelanin synthesis is stimulated by $\alpha$-MSH and adrenocorticotropin hormone (ACTH), 2 agonists of the MC1R, 
and the production of eumelanin and pheomelanin is regulated by $\alpha-\mathrm{MSH}$ by way of MC1R (32). $\alpha$-MSH and ACTH have as a common precursor the proopiomelanocortin (POMC), a synthetic protein of pituitary gland. Moreover, $\alpha-\mathrm{MSH}$ is also formed in the epidermal keratinocytes whose production is locally, paracrine, adjusted (33). Hyperpigmentation of the face and neck skin, known as melasma, occurs in fertile women and appears most frequently as a result of pregnancy and exposure to the sun, due to increased production of melanin and melanocytosis (34).

Hormonal changes in pregnancy (increased plasma levels of $\alpha$ - and $\beta$-MSH, estrogen, progesterone and $\beta$-endorphin) stimulate melanocytes to produce excess melanin (35). Also, human placental lipids upregulate tyrosinase activity and increase melanin synthesis. During pregnancy, plasmatic levels of ACTH and cortisol are increased. CRH stimulates placental production of $\alpha-\mathrm{MSH}$ and POMC. After 3 days postpartum, the plasmatic level of POMC returns to normal $(36,37)$.

The sun ultraviolet radiation stimulates the genic expression of POMC and increases the POMC production. The increase of the $\alpha$-MSH or ACTH quantity activates MC1R, leading to an increase of the intracellular AMPc quantity, and the pheomelanin synthesis is exchanged by eumelanin synthesis. Exposure to the sun ultraviolet radiation determines at the skin level two types of reaction: on the one hand, the immediate pigmentation, which appears after a couple of minutes following exposure to the sun and disappears after $6-8 \mathrm{~h}$ and is the result of the oxidation of the pre-existing melanin or of its precursors, and on the other hand, the delayed pigmentation, which appears after 48-72 $\mathrm{h}$ following exposure to the sun and is persistent, being the result of producing a new quantity of melanin. Melanogenesis is also stimulated by a series of cytokines with a paracrine effect such as prostaglandin E2 and D2 (37,38), stem cell factor (39), endotelin-1 (40), oxide nitric (41), histamine (42), $\mathrm{Cu}$ - and As-ions and is inhibited by thiamin, hydroquinone, ascorbic acid, Ag- and $\mathrm{Hg}$-ions.

\section{Synthesis of the melanic pigments}

Necessary for the synthesis of the catecholamines, the tyrosine amino-acid and its hydroxylated DOPA product, represent the starting point of the biosynthesis of the melanic pigments. Raper and Mason, between 1930 and 1940, were the first to establish the biosynthesis path of eumelanin (43). Melanin is formed following the cascading reactions, enzymatically catalyzed. The melanic pigment of the yellowish-reddish colour, pheomelanin, soluble polymer in alkaline solutions, results from the oxidative polymerization of the cysteinyldopa (formed through the condensation of the cysteine amino-acid with the dopaquinone). Eumelanin, of the brownish towards blackish colour, insoluble polymer in alkaline solutions, are formed through the oxidative polymerization of 5,6-dihydroxyindole. The hydroxylation of the L-tyrosine at the L-DOPA is catalyzed by the tyrosinase (TYR) and by a series of proteins related to the tyrosinase (44).

The tyrosinase, a membranal protein of the 3rd type (45), is an indispensable enzyme of melanogenesis. It is located only in the membrane of the melanosomes, cellular organelles specific of the melanocytes. The enzyme is synthesized at the level of the endoplasmic reticulum, and then packed in the blisters of the Golgi apparatus, from where it is transported in the melanosomes, the synthesis place of the melanin. The tyrosinase activity is correlated with the melanin production degree. The synthesis of the melanosomes and the tyrosinase activity is stimulated by the L-tyrosine (46). The concentration of L-tyrosine and that of the L-DOPA controls the homeostasis of the melanogenic system, and the melanocytes coordinates this system not only locally but also overall (47).

Azelaic acid inhibits the synthesis of DNA and mitochondrial enzymes, has an effect on tyrosinase and reduces the production of free radicals that contribute to hyperpigmentation of the skin (48). Due to the direct cytotoxic effect on abnormal melanocytes, azelaic acid is useful in the treatment of hyperpigmentation (it does not affect normal pigmentation of the skin and does not cause depigmentation).

In the human brain, neuromelanin is formed following the oxidation of the dopamine in dopaquinone, reaction catalyzed by the tyrosinase. The formation of excess dopaquinone leads to the neural disorder and death (49). Thus, it is suggested the involvement of the tyrosinase in the neuro-degeneration associated to the Parkinson disease (50) and Huntington chorea $(51,52)$. Together with the tyrosinase, in the transformation of the tyrosine in melanic pigments, 2 more proteins are involved, named dopachrometautomerasis, represented by the protein 1 related to the tyrosine (TRP-1) and protein 2 related to the tyrosine (TRP-2). Like the tyrosinase, TRP-1 and TRP-2 are found in the melanosomes. The role of these proteins is crucial because it catalyzes the reactions which produce the eumelanin. TRP-1 behaves like a peroxidase and grants protection against the oxidative stress $(13,53)$.

\section{Conclusion}

A more accurate knowledge of melanogenesis physiology helps to understand the pathophysiological mechanisms of dermatological diseases which appear as a result of melanogenesis.

\section{Acknowledgements}

Not applicable.

Funding

No funding was received.

\section{Availability of data and materials}

Not applicable.

\section{Authors' contributions}

MAM, DB, and ILS contributed to the conception and design of the study, while DNS, DCB, GS, and NM contributed to the data analysis and the critical interpretation. MAM and DB were responsible for drafting the manuscript and revising it critically for important intellectual content, while DNS, DCB, GS, NM, and ILS focused on the revision of particular aspects of important intellectual content. All the authors declare their 
final approval of the version to be published and their agreement to be accountable for all aspects of the work in ensuring that questions related to the accuracy or integrity of any part of the work are appropriately investigated and resolved.

\section{Ethics approval and consent to participate}

Not applicable.

\section{Patient consent for publication}

Not applicable.

\section{Competing interests}

The authors declare that they have no competing interests.

\section{References}

1. Bonaventure J, Domingues MJ and Larue L: Cellular and molecular mechanisms controlling the migration of melanocytes and melanoma cells. Pigment Cell Melanoma Res 26: 316-325, 2013.

2. Schadendorf D, Fisher DE, Garbe C, Gershenwald JE, Grob JJ, Halpern A, Herlyn M, Marchetti MA, McArthur G, Ribas A, et al: Melanoma. Nat Rev Dis Primers 1: 15003, 2015.

3. Sviderskaya EV, Hill SP, Balachandar D, Barsh GS and Bennett DC: Agouti signaling protein and other factors modulating differentiation and proliferation of immortal melanoblasts. Dev Dyn 221: 373-379, 2001

4. Panzella L, Ebato A, Napolitano A and Koike K: The late stages of melanogenesis: Exploring the chemical facets and the application opportunities. Int J Mol Sci 19: E1753-E1769, 2018.

5. Bastian BC: The molecular pathology of melanoma: An integrated taxonomy of melanocytic neoplasia. Annu Rev Pathol 9 239-271, 2014

6. Cichorek M, Wachulska M, Stasiewicz A and Tymińska A: Skin melanocytes: Biology and development. Postepy Dermatol Alergol 30: 30-41, 2013

7. Costin GE and Hearing VJ: Human skin pigmentation: Melanocytes modulate skin color in response to stress. FASEB J 21: 976-994, 2007.

8. Lin JY and Fisher DE: Melanocyte biology and skin pigmentation. Nature 445: 843-850, 2007.

9. Wu S, Han J, Laden F and Qureshi AA: Long-term ultraviolet flux, other potential risk factors, and skin cancer risk: A cohort study. Cancer Epidemiol Biomarkers Prev 23: 1080-1089, 2014.

10. Okazaki S, Funasaka Y, Wakamatsu K, Kawana S and Saeki H: Effect of infrared radiation A on photoaged hairless mice harboring eumelanin and pheomelanin in the epidermis. J Dermatol 42: 382-390, 2015.

11. Neagu M, Caruntu C, Constantin C, Boda D, Zurac S, Spandidos DA and Tsatsakis AM: Chemically induced skin carcinogenesis: Updates in experimental models (Review). Oncol Rep 35: 2516-2528, 2016.

12. Lupu M, Caruntu A, Caruntu C, Papagheorghe LML, Ilie MA, Voiculescu V, Boda D, Constantin C, Tanase C, Sifaki M, et al: Neuroendocrine factors: The missing link in non melanoma skin cancer (Review). Oncol Rep 38: 1327-1340, 2017.

13. Videira IF, Moura DF and Magina S: Mechanisms regulating melanogenesis. An Bras Dermatol 88: 76-83, 2013.

14. Slominski AT, Zmijewski MA, Skobowiat C, Zbytek B, Slominski RM and Steketee JD: Sensing the environment: Regulation of local and global homeostasis by the skin's neuroendocrine system. Adv Anat Embryol Cell Biol 212: 1-115, 2012.

15. Virador VM, Muller J, Wu X, Abdel-Malek ZA, Yu ZX, Ferrans VJ, Kobayashi N, Wakamatsu K, Ito S, Hammer JA, et al: Influence of $\alpha$-melanocyte-stimulating hormone and ultraviolet radiation on the transfer of melanosomes to keratinocytes. FASEB J 16: 105-107, 2002.

16. Yuan $\mathrm{XH}$ and Jin $\mathrm{ZH}$ : Paracrine regulation of melanogenesis. Br J Dermatol 178: 632-639, 2018.
17. Delevoye C: Melanin transfer: The keratinocytes are more than gluttons. J Invest Dermatol 134: 877-879, 2014.

18. Brenner $M$ and Hearing VJ: The protective role of melanin against UV damage in human skin. Photochem Photobiol 84: 539-549, 2008

19. Marks MS and Seabra MC: The melanosome: Membrane dynamics in black and white. Nat Rev Mol Cell Biol 2: 738-748, 2001.

20. $\mathrm{Wu} \mathrm{X}$ and Hammer JA: Melanosome transfer: It is best to give and receive. Curr Opin Cell Biol 29: 1-7, 2014.

21. Boda D: Cellomics as integrative omics for cancer. Curr Proteomics 10: 237-245, 2013.

22. Slominski A, Wortsman J, Plonka PM, Schallreuter KU, Paus R and Tobin DJ: Hair follicle pigmentation. J Invest Dermatol 124: 13-21, 2005.

23. Fischer M, Glanz D, Urbatzka M, Brzoska T and Abels C: Keratinocytes: A source of the transmitter L-glutamate in the epidermis. Exp Dermatol 18: 1064-1066, 2009.

24. Slominski A and Paus R: Melanogenesis is coupled to murine anagen: Toward new concepts for the role of melanocytes and the regulation of melanogenesis in hair growth. J Invest Dermatol 101: 90S-97S, 1993.

25. Tobin DJ and Paus R: Graying: Gerontobiology of the hair follicle pigmentary unit. Exp Gerontol 36: 29-54, 2001.

26. Pandiani C, Béranger GE, Leclerc J, Ballotti R and Bertolotto C: Focus on cutaneous and uveal melanoma specificities. Genes Dev 31: 724-743, 2017.

27. Marinescu SA, Tatu AL, Mihai IR and Giuglea C: Correlations between clinics, dermoscopy and histopathology in a female with two dermatofibromas-a case report. Rom J Morphol Embryol 57: 323-326, 2016.

28. Takeda K, Takahashi NH and Shibahara S: Neuroendocrine functions of melanocytes: Beyond the skin-deep melanin maker. Tohoku J Exp Med 211: 201-221, 2007.

29. Zecca L, Casella L, Albertini A, Bellei C, Zucca FA, Engelen M, Zadlo A, Szewczyk G, Zareba M and Sarna T: Neuromelanin can protect against iron-mediated oxidative damage in system modeling iron overload of brain aging and Parkinson's disease. J Neurochem 106: 1866-1875, 2008.

30. Carneiro F, Kruithof BP, Balani K, Agarwal A, Gaussin V and Kos L: Relationships between melanocytes, mechanical properties and extracellular matrix composition in mouse heart valves. J Long Term Eff Med Implants 25: 17-26, 2015.

31. Levin MD, Lu MM, Petrenko NB, Hawkins BJ, Gupta TH, Lang D, Buckley PT, Jochems J, Liu F, Spurney CF, et al: Melanocyte-like cells in the heart and pulmonary veins contribute to atrial arrhythmia triggers. J Clin Invest 119: 3420-3436, 2009.

32. Beavan S, Horner A, Bord S, Ireland D and Compston J: Colocalization of glucocorticoid and mineralocorticoid receptors in human bone. J Bone Miner Res 16: 1496-1504, 2001.

33. Abdel-Malek Z, Swope VB, Suzuki I, Akcali C, Harriger MD, Boyce ST, Urabe K and Hearing VJ: Mitogenic and melanogenic stimulation of normal human melanocytes by melanotropic peptides. Proc Natl Acad Sci USA 92: 1789-1793, 1995.

34. Tatu AL: The skin and nevi pigmentation during pregnancy. J Am Acad Dermatol 66: AB148, 2012.

35. Tatu AL: Melasma and pregnancy. Australas J Dermatol 53: 37, 2011.

36. Tatu AL: Skin tags and pregnancy. Australas J Dermatol 51: A48-A50, 2010.

37. Tatu AL: Dermoscopic structural changes of nevi during pregnancy related to location. J Am Acad Dermatol 64: AB75, 2011.

38. Nordlund JJ, Collins CE and Rheins LA: Prostaglandin E2 and D2 but not MSH stimulate the proliferation of pigment cells in the pinnal epidermis of the DBA/2 mouse. J Invest Dermatol 86: 433-437, 1986.

39. Suzuki I, Cone RD, Im S, Nordlund J and Abdel-Malek ZA: Binding of melanotropic hormones to the melanocortin receptor MC1R on human melanocytes stimulates proliferation and melanogenesis. Endocrinology 137: 1627-1633, 1996.

40. Imokawa G, Miyagishi M and Yada Y: Endothelin-1 as a new melanogen: Coordinated expression of its gene and the tyrosinase gene in UVB-exposed human epidermis. J Invest Dermatol 105: 32-37, 1995.

41. Schauer E, Trautinger F, Köck A, Schwarz A, Bhardwaj R, Simon M, Ansel JC, Schwarz T and Luger TA: Proopiomelanocortin-derived peptides are synthesized and released by human keratinocytes. J Clin Invest 93: 2258-2262, 1994. 
42. Yoshida M, Takahashi Y and Inoue S: Histamine induces melanogenesis and morphologic changes by protein kinase A activation via $\mathrm{H} 2$ receptors in human normal melanocytes. J Invest Dermatol 114: 334-342, 2000.

43. Sugumaran M: Reactivities of quinone methides versus o-quinones in catecholamine metabolism and eumelanin biosynthesis. Int J Mol Sci 17: 1576-1579, 2016.

44. Niu $\mathrm{C}$ and Aisa HA: Upregulation of melanogenesis and tyrosinase activity: Potential agents for vitiligo. Molecules 22: 1303-1305, 2017.

45. Rzepka Z, Buszman E, Beberok A and Wrześniok D: From tyrosine to melanin: Signaling pathways and factors regulating melanogenesis. Postepy Hig Med Dosw 70: 695-708, 2016.

46. D'Ischia M, Wakamatsu K, Napolitano A, Briganti S, Garcia-Borron JC, Kovacs D, Meredith P, Pezzella A, Picardo M, Sarna T, et al: Melanins and melanogenesis: Methods, standards, protocols. Pigment Cell Melanoma Res 26: 616-633, 2013.

47. Slominski A, Zmijewski MA and Pawelek J: L-tyrosine and L-dihydroxyphenylalanine as hormone-like regulators of melanocyte functions. Pigment Cell Melanoma Res 25: 14-27, 2012
48. Hollinger JC, Angra K and Halder RM: Are natural ingredients effective in the management of hyperpigmentation? A systematic review. J Clin Aesthet Dermatol 11: 28-37, 2018.

49. Pillaiyar T, Manickam M and Namasivayam V: Skin whitening agents: Medicinal chemistry perspective of tyrosinase inhibitors. J Enzyme Inhib Med Chem 32: 403-425, 2017.

50. Caruntu C, Boda D, Constantin C, Caruntu A and Neagu M: Catecholamines increase in vitro proliferation of murine B16F10 melanoma cells. Acta Endocrinol (Copenh) 10: 545-558, 2014.

51. Diaconeasa A, Boda D, Solovan C, Enescu DM, Vîlcea AM and Zurac S: Histopathologic features of Spitzoid lesions in different age groups. Rom J Morphol Embryol 54: 51-62, 2013.

52. Hasegawa T: Tyrosinase-expressing neuronal cell line as in vitro model of Parkinson's disease. Int J Mol Sci 11: 1082-1089, 2010.

53. Zurac S, Neagu M, Constantin C, Cioplea M, Nedelcu R, Bastian A, Popp C, Nichita L, Andrei R, Tebeica T, et al: Variations in the expression of TIMP1, TIMP2 and TIMP3 in cutaneous melanoma with regression and their possible function as prognostic predictors. Oncol Lett 11: 3354-3360, 2016. 